\title{
HISTOPATHOLOGICAL FINDINGS OF THE URINARY BLADDER EPITHELIUM IN AGED DOGS
}

\author{
Kunihiko Tsunemi*, Seiichiro Ozono, Hisako Yamaguchi, Yoshiki \\ Hayashi, Katsuhiro Babaya, Yoshihiko Hirao, and Eigoro Okajima \\ Department of Urology, Nara Medical University
}

Shoji Fukushima

1st Department of Pathology, Osaka City University, Medical School

Rikio Niki

Toxicology Research Laboratories, Chugai Pharmaceutical Co., Ltd.

\begin{abstract}
Apparently normal urinary bladder of beagle dogs of both sexes were examined histopathologically. Materials were obtained from fifty autopsied aged beagle dogs and six autopsied young beagle dogs. Changes of urinary bladder epithelium were classified into five types: Brunn's nest, squamous metaplasia, lymphocytic infiltration, epithelial hyperplasia, and atypia. Brunn's nests in aged dogs were found at all ages and in both sexes. Squamous metaplasia in aged dogs was found in $25.0 \%$ of males and 50.0\% of females. Scattered lymphocytic infiltration in aged dogs could be observed in $18.0 \%$ of both sexes. Epithelial hyperplasia and atypia in aged dogs were found in $82.0 \%$ and $28.0 \%$ of cases, respectively ; however, no difference between sexes was found. Sites of predilection for Brunn's nests were the trigone and anterior wall; however, those for other types of lesion were not found. As for young dogs, Brunn's nests were found in $66.7 \%$ of both sexes, and sites of predilection were the trigone and anterior wall; the other lesions were not observed. These chronic changes of urinary bladder epithelium in aged beagle dogs should be considered in the studies of bladder carcinogenesis and natural history of bladder tumor in dogs. (J Toxicol Pathol 7: 73 80, 1994)
\end{abstract}

Key words : Urinary bladder epithelium, Aged changes, Beagle dogs

\section{Introduction}

Human bladder carcinoma can be divided into two types: papillary, non-invasive carcinoma and non-papillary, invasive carcinoma. The natural history has not as yet been adequately clarified for either of the two types. In the past, the development of experimental models of bladder carcinoma have been attempted, using dogs and rodent animals such as mice and rats. The establishment of an animal model of bladder carcinoma

常深邦彦 大園誠一郎 山口尚子 林 美樹 馬場谷勝廣 平尾佳彦 岡島英五郎 福島昭治 二木力夫

Accepted for publication : October 10, 1993

Mailing address : Eigoro Okajima, Department of Urology, Nara Medical University, 840 Shijo-cho, Kashihara, Nara 634, Japan. similar to human bladder carcinoma is important for analyzing various factors associated with the development and progression of bladder carcinoma and for obtaining basic data on the clinical diagnosis and treatment. We established a dog model for bladder carcinogenesis using $\mathrm{N}$-butyl$\mathrm{N}$-(4-hydroxybutyl)nitrosamine (BBN) and reported that BBN induce papillary non-invasive bladder carcinoma after a long period of administration at low doses and non-papillary invasive bladder carcinoma after a short period at high doses'. In addition, we infused $\mathrm{N}$-methyl-Nnitrosourea (MNU) into the bladder of dogs, administered BBN orally and observed the development of carcinoma in situ (CIS) ${ }^{2}$. Thus, two types of bladder carcinoma similar to those in humans have been induced in dogs. 
In Japan, human bladder carcinoma occurs most frequently in the age range between 60 and 80. Some investigators have reported changes in the bladder epithelium observed in autopsied elderly individuals free of epithelial tumor of the urinary tract ${ }^{3}$. However, no reports have been published regarding age-related changes of the bladder epithelium in dogs. We recently conducted a histopathological study of apparently normal urinary bladder epithelium of aged beagle dogs to classify mucosal changes, analyze their distribution, and to examine the relationship of these changes to sex and age.

\section{Materials and Methods}

Fifty beagle dogs between 8 and 13 years of age, which had been used as breeding dogs at CSK Research Park Ltd. (Suwa, Japan) were employed for this study. Of 50 dogs, 8 were males and 42 females. After weaning, they were given only commercial dog diet (CD-5, Japan Clea Inc., Tokyo, Japan) until they were sacrificed. Before sacrifice, none of the dogs showed any sign of bladder abnormalities or received any surgical manipulation. The control group consisted of six 8- or 9-month-old beagles, 3 males and 3 females, which had been raised at the above-mentioned animal farm (Table 1).

Under deep anesthesia with pentobarbiturate (Nembutal ${ }^{8}$ ), all dogs were sacrificed without causing any pain. The urinary bladder was immediately inflated in situ with $10 \%$ phosphatebuffered formalin solution. Subsequently, the

Table 1. Age and Sex Distribution of Beagle Dogs

\begin{tabular}{cccc}
\hline Age (Yrs) & Male & Female & Total \\
\hline$\sim 1$ & 3 & 3 & $6^{*}$ \\
\hline 8 & 0 & 3 & 3 \\
9 & 3 & 12 & 15 \\
10 & 3 & 21 & 24 \\
11 & 0 & 6 & 6 \\
12 & 0 & 0 & 0 \\
13 & 2 & 0 & 2 \\
\hline Total & 11 & 45 & 56 \\
\hline
\end{tabular}

* Those served as control group. urethra was ligated and the bladder was immersed in the same fixative solution. The fixed bladder was incised, according to the General Rule for Clinical and Pathological Studies on Bladder Cancer $^{4}$, to prepare serial sections at intervals of about $5 \mathrm{~mm}$. From each animal, 44 to 80 sections were embedded in paraffin and stained with hematoxylin and eosin. Each tissue block was cut at two different levels.

The bladder was histologically classified, according to the Atlas of Tumor Pathology (AFIP) $^{5}$ and the above-mentioned General Rule ${ }^{4}$.

\section{Results}

\section{Classification of the mucosal epithelium}

Changes in the mucosal epithelium were classified into the following five types, in comparison to a normal mucosal epithelium which had approximately three transitional cell layers with large covering cells (Fig. 1).

Type 1: Brunn's nests

Foci composed of transitional epithelial cells showed nodular growth within the lamina propria. No atypia was observed (Fig. 2).

Type 2 : Squamous metaplasia

The mucosal epithelium was partly replaced with squamous epithelium. However, stratification of the squamous epithelium was rare and keratinization was absent (Fig. 3).

Type 3: Lymphocytic infiltration

Local or diffuse infiltration of lymphocytes into the lamina propria was seen. Lymphoid follicles were noted in three dogs in which abnormalities of the mucosal surface were macroscopically visible (Fig. 4).

Type 4: Simple hyperplasia

The epithelium of the bladder mucosa showed stratification into 4 to 6 layers, although cellular atypia was hardly seen (Fig. 5).

Type 5: Atypia

Epithelial cells are atypical, although papillary growth of the mucosal epithelium was absent. This change was noted relatively often in areas showing simple hyperplasia (Fig. 6). 


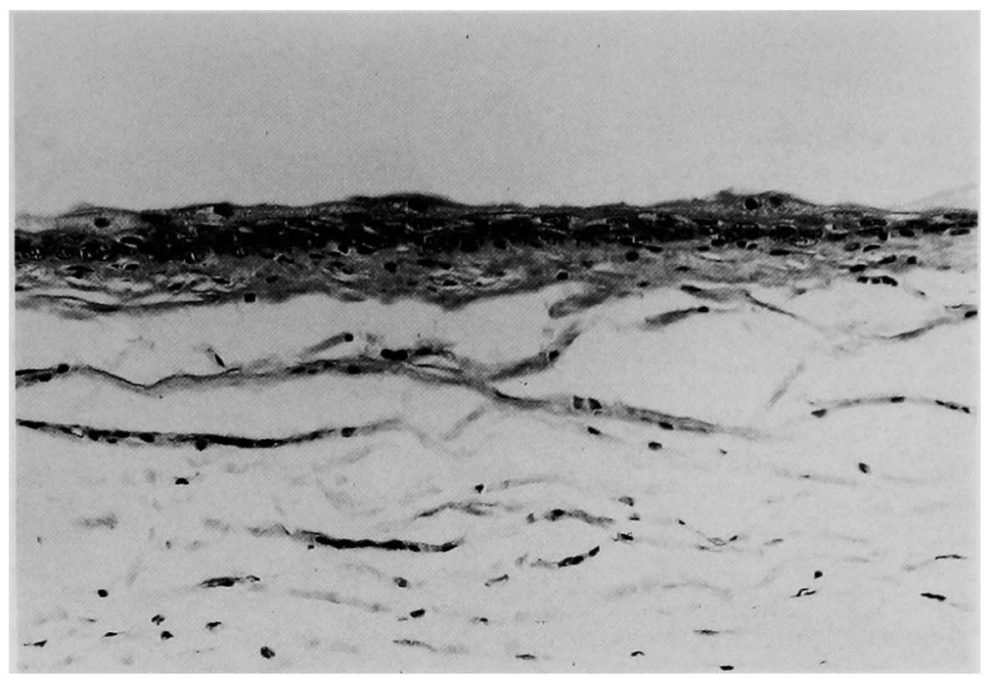

Fig. 1. Normal transitional epithelium. Note the large superficial umbrella cells stretching over many cells of the adjacent lower epithelial layer. HE $\times 200$.

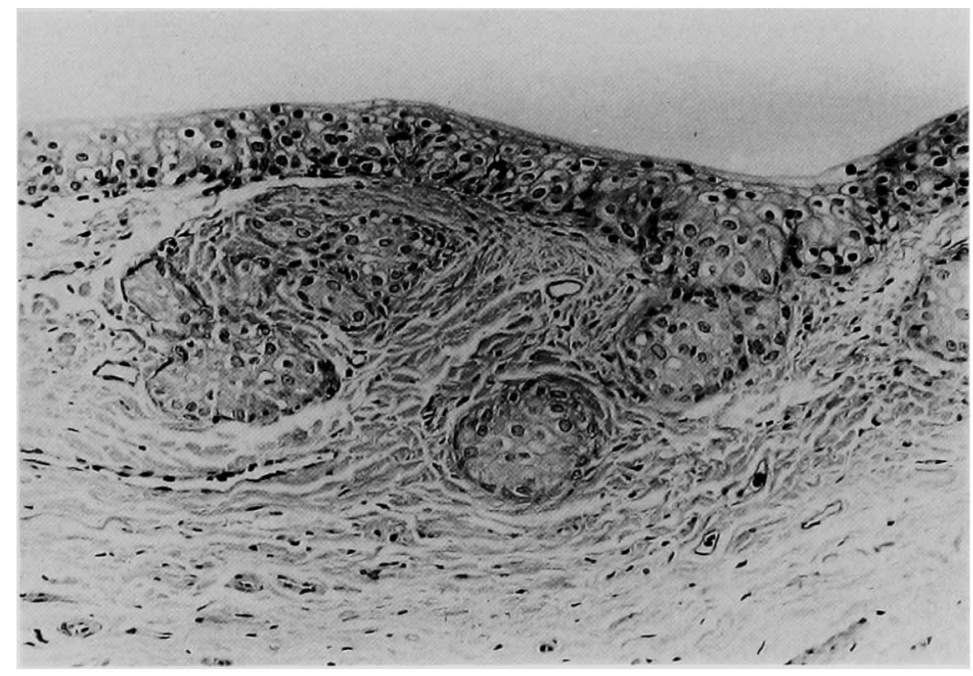

Fig. 2. Typical Brunn's nests. Nest of transitional cells lying in the lamina propria. HE $\times 200$.

Correlation of changes in the mucosal epithelium to age and sex (Figs. 7 and 8)

Brunn's nests were seen in all males and females from the aged dog group. In the young dog group, $2(66.7 \%)$ of 3 males and $2(66.7 \%)$ of 3 females had Brunn's nests.

Squamous metaplasia was noted in $23(46.0 \%)$ of 50 aged dogs. It was present in 2 (25.0\%) of 8 aged male dogs and in 21 (50.0\%) of 42 aged female dogs. In males, squamous metaplasia was only noted at age 10. In females, it was noted at ages
9 (7/12 dogs, 58.3\%), 10 (9/21 dogs, $42.9 \%)$ and 11 ( $5 / 6$ dogs, $83.3 \%)$. In females, the incidence of squamous metaplasia increased with age. Neither males nor females from the young group showed squamous metaplasia.

Lymphocytic infiltration was seen in 9 (18.0\%) of 50 aged dogs. It was seen in 1 (12.5\%) of the 8 aged males and 8 (19.0\%) of 42 aged females. In males, lymphocytic infiltration was only seen at age 10 (1/3 dogs, 33.3\%). In females, it was seen at ages 8 (1/3 dogs, 33.3\%), 9 (4/12 dogs, 33.3\%), $10(2 / 21$ dogs, 9.5\%) and 11 (1/6 dogs, 16.7\%). 


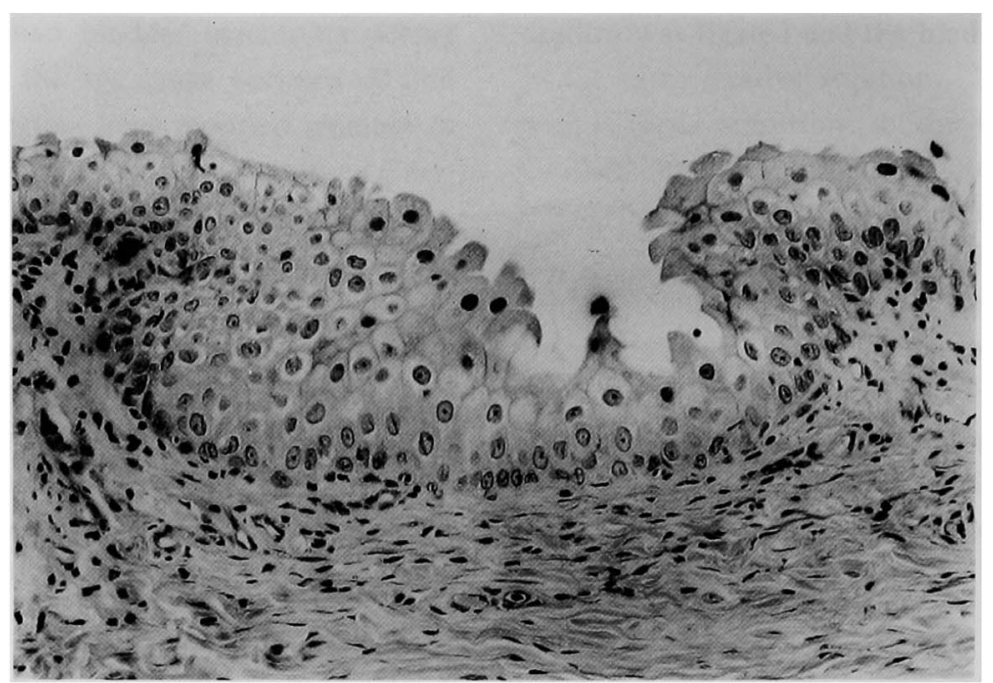

Fig. 3. Squamous metaplasia. The surface urothelium is replaced by squamous epithelium but it is not keratinized. HE $\times 200$.

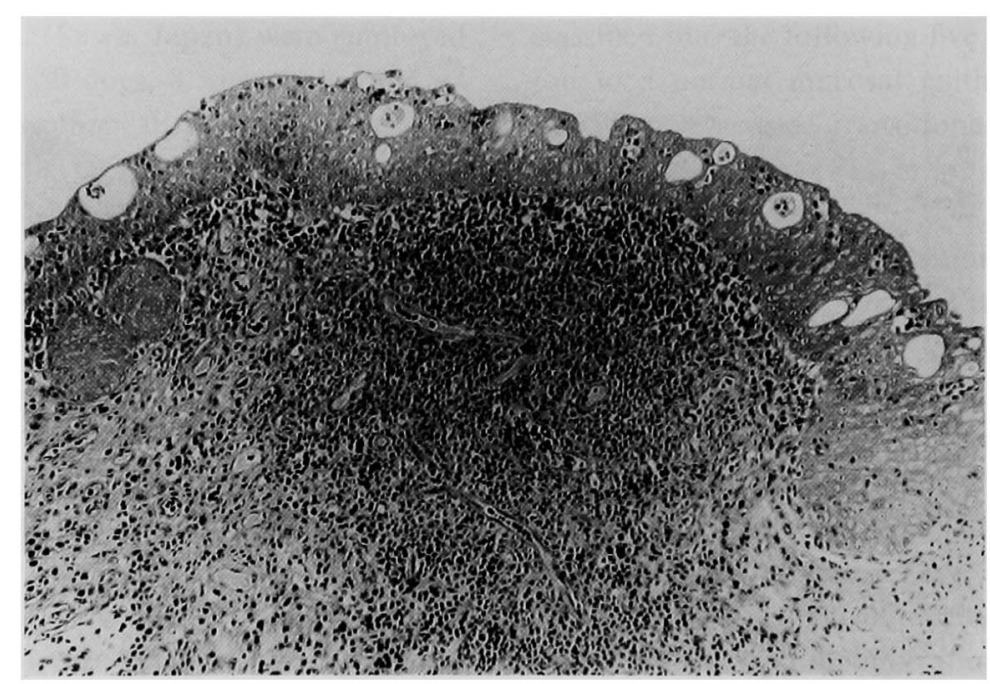

Fig. 4. Lymphocytic infiltration. Formation of lymphoid follicle in the lamina propria and reactive proliferation are observed in the epithelium. HE $\times 100$.

Neither males nor females in the young group showed lymphocytic infiltration.

Simple hyperplasia was noted in 41 (82.0\%) of 50 aged dogs. The incidence did not differ between males and females. In males, simple hyperplasia was noted at ages 9 (all dogs), 10 (all dogs), and 13 (1/2 dogs, 50.0\%). In females, it was noted at ages 8 (1/3 dogs, 33.3\%), 9 (11/12 dogs, 91.7\%), 10 (17/21 dogs, 81.0\%), and 11 (5/6 dogs, 83.3\%). Neither males nor females from the young group showed simple hyperplasia.

Atypia of the mucosal epithelium was noted in $14(28.0 \%)$ of 50 aged dogs. The incidence did not differ between males and females. At ages 9 and 10 , the incidence of this change ranged from 33.3 to $41.7 \%$ in both males and females. In the female group, this abnormality was absent at ages 8 and 11 . In the male group, this abnormality was absent at age 13. Neither males nor females from the young group showed this abnormality.

\section{Distribution of changes in the mucosal epithelium} (Table 2)

In the aged dogs, Brunn's nests were visible in 


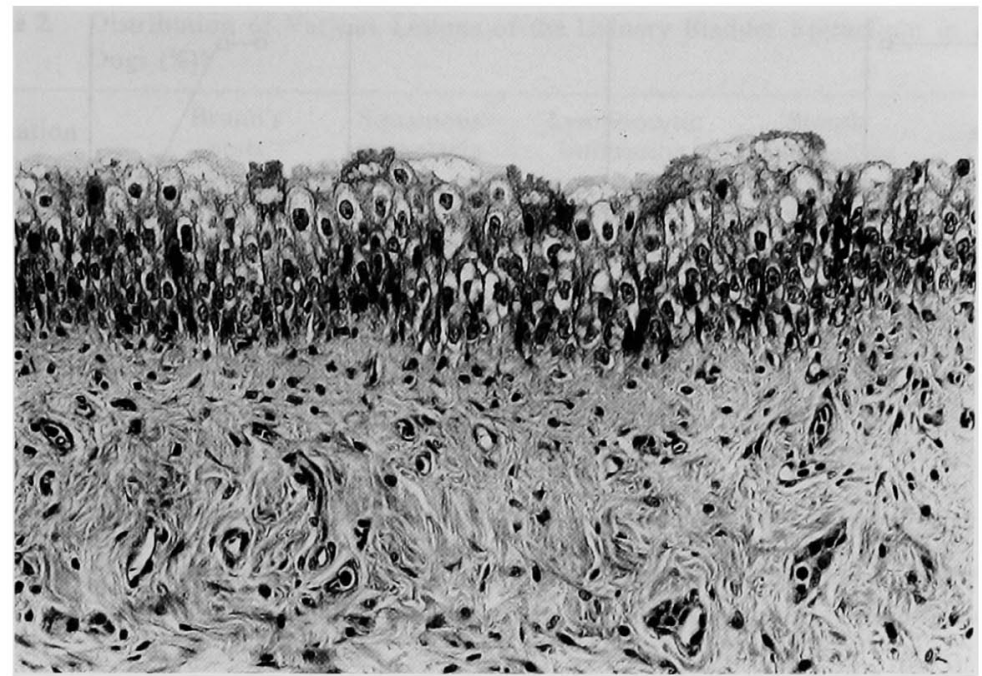

Fig. 5. Simple hyperplasia. Number of cell layers of the transitional epithelium increased, but no atypia is noted. HE $\times 200$.

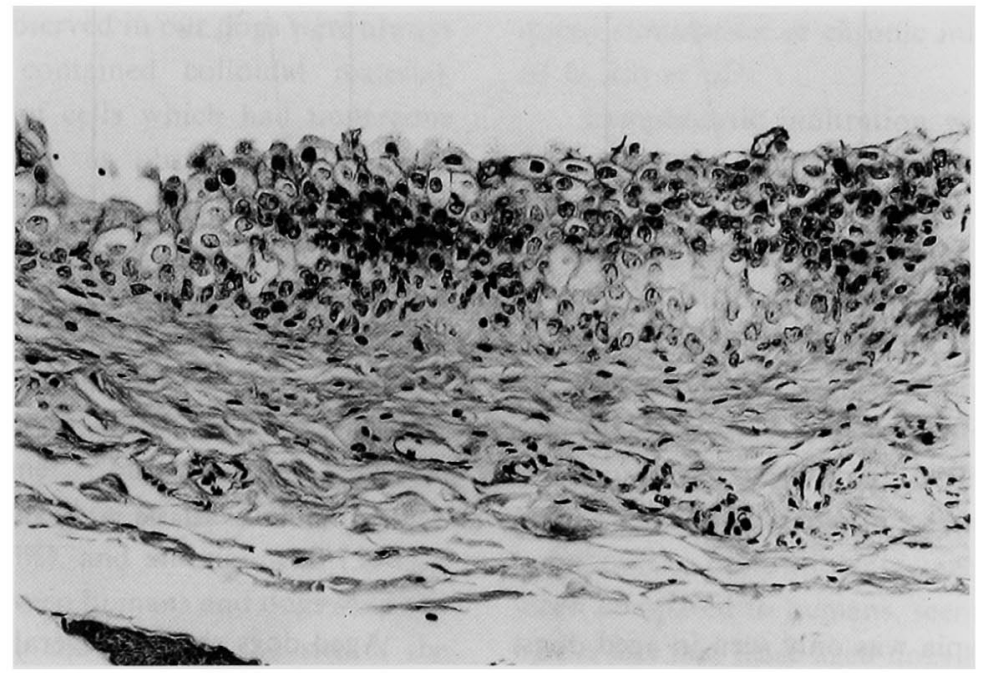

Fig. 6. Atypia. Besides an increase in the number of cell layers, the component cells show an occasional small nucleus hyperchromasia, and superficial cells are not present. HE $\times 200$.

all regions of the bladder mucosa. They were more often located in the trigone $(42 / 50 \mathrm{dogs}$, $84.0 \%)$ and the anterior wall (38/50 dogs, $76.0 \%)$ and less frequently in the dome (7/50 dogs, 14.0\%). In the 4 young dogs with Brunn's nests, the nests were distributed in all regions excluding the neck and the right lateral wall. In these 4 dogs, Brunn's nests were more frequently seen in the trigone (3/4 dogs, 75.0\%) and the anterior wall (3/ 4 dogs, $75.0 \%)$.

Squamous metaplasia was only seen in aged dogs. Although no particular region had exceed- ingly high incidences of this abnormality.

Lymphocytic infiltration was only seen in aged dogs. In the male group, it was only seen in the bladder neck of a dog. In the female group, it was seen in almost all regions of 4 dogs and in one or two regions of 4 dogs.

Simple hyperplasia was only seen in aged dogs. Of 41 dogs with simple hyperplasia, 4 (9.8\%) had this abnormality in the neck. In the remaining 37 dogs, simple hyperplasia was distributed in all regions, with incidences of individual regions ranging from 39.0 to $61.0 \%$. 


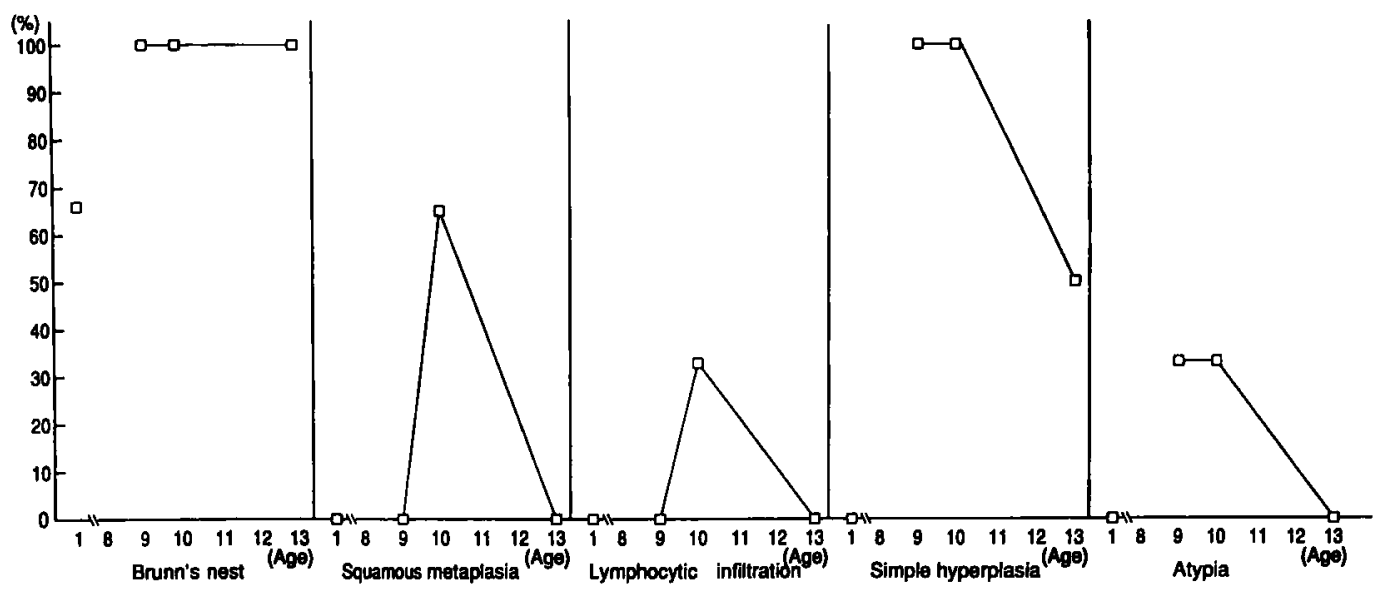

Fig. 7. Incidence of various lesions of the urinary bladder epithelium as related to age of male dogs.

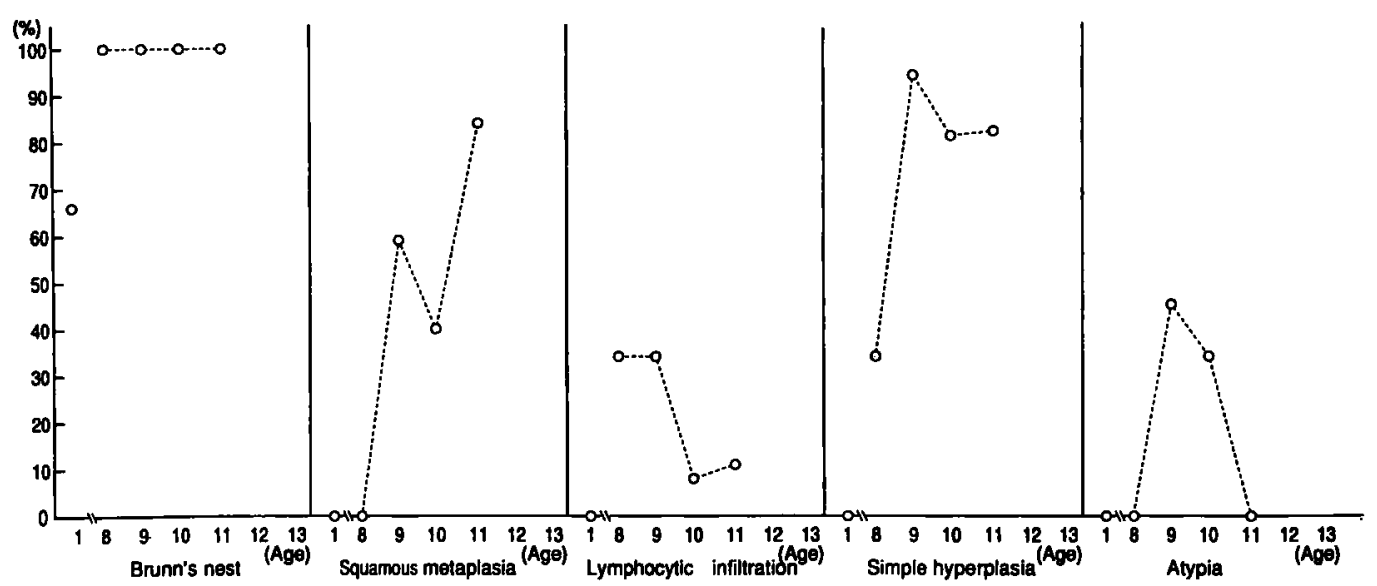

Fig. 8. Incidence of various lesions of the urinary bladder epithelium as related to age of female dogs.

Epithelial atypia was only seen in aged dogs. It was distributed in all regions of the mucosa, with a particularly high incidence in the anterior wall (9/14 dogs, 64.3\%).

\section{Discussion}

In aged dogs, between 8 and 13 years of age, and young dogs, below 1 year, of both sexes, we examined changes of the bladder epithelium under a light microscope.

In the young dog group, both males and females had Brunn's nests at an incidence of $66.7 \%$. The incidence was high in the trigone and the anterior wall, although no other changes were observed.
Aged dogs showed several changes. Brunn's nests was the most frequent change, which was seen in all males and females from the aged dog group. This proliferative change was seen in all regions of the mucosa, although sites of predilection were the trigone and the anterior wall. It has been reported that Brunn's nests in humans do not suggest precancerous lesions ${ }^{6.7}$. In the present study, both males and females from the young dog group showed this change at an incidence of 66.7\%. These results suggest that Brunn's nests represent a benign proliferative change. The incidence of this change in our aged dogs was $100 \%$, which is closer to the figure reported for humans $(93.6 \%)^{7}$. The sites where this change occurred frequently in the present study, the trigone and the anterior wall, 
Table 2. Distribution of Various Lesions of the Urinary Bladder Epithelium in Aged Dogs (\%)*

\begin{tabular}{cccccc}
\hline Location & $\begin{array}{c}\text { Brunn's } \\
\text { nests }\end{array}$ & $\begin{array}{c}\text { Squamous } \\
\text { metaplasia }\end{array}$ & $\begin{array}{c}\text { Lymphocytic } \\
\text { infiltration }\end{array}$ & $\begin{array}{c}\text { Simple } \\
\text { hyperplasia }\end{array}$ & Atypia \\
\hline Neck & $33(66.0)$ & $1(4.3)$ & $3(33.3)$ & $4(9.8)$ & $0-$ \\
Trigone & $42(84.0)$ & $3(13.0)$ & $4(44.4)$ & $23(56.1)$ & $2(14.3)$ \\
Posterior wall & $16(32.0)$ & $10(43.5)$ & $5(55.6)$ & $20(48.8)$ & $6(42.9)$ \\
R-lateral wall & $26(52.0)$ & $8(34.8)$ & $4(44.4)$ & $16(39.0)$ & $4(28.6)$ \\
L-lateral wall & $30(60.0)$ & $4(17.4)$ & $5(55.6)$ & $18(43.9)$ & $6(42.9)$ \\
Dome & $7(14.0)$ & $12(52.2)$ & $4(44.4)$ & $19(46.3)$ & $3(21.4)$ \\
Anterior wall & $38(76.0)$ & $9(39.1)$ & $6(66.7)$ & $25(61.0)$ & $9(64.3)$ \\
\hline Total & $50(100.0)$ & $23(46.0)$ & $9(18.0)$ & $41(82.0)$ & $14(28.0)$ \\
\hline
\end{tabular}

* Percentages represent the proportion of cases of each given lesion found in various sites.

were identical to those previously reported ${ }^{7}$. However, the incidence of this change in the dome of aged dogs was as low as $14.0 \%$. Histologically, the Brunn's nests observed in our dogs were always solid and never contained colloidal material. Furthermore, foci of cells which had undergone squamous metaplasia, as observed in humans ${ }^{6}$, were absent in our dogs.

Squamous metaplasia was observed in about half of aged dogs. The incidence of this change in females was double that in males and it tended to increase with age. Although previous studies in humans demonstrated high incidences of this change in the trigone ${ }^{6-9}$, our aged dogs had high incidences of this change in the dome (52.2\%), posterior wall (43.5\%), and anterior wall (39.1\%). This difference between humans and dogs seems to be attributable to a difference in the site of the bladder where it is in contact with urine or stimulated by urine between humans who walk on 2 legs and dogs which walk on 4 legs. When examined histologically, the transitional epithelium of aged dogs had been partially replaced with squamous epithelium, but stratification was rare and keratinization was not seen at all. Thus, the changes of the transitional epithelium in aged dogs were less severe than those reported for humans. It cannot be ruled out that squamous metaplasia is caused by stimulation with estrogen $^{6,8}$ or by chronic infection ${ }^{9}$. However, of the 23 aged dogs with squamous metaplasia, only 4 showed lymphocytic infiltration. Although we did not measure estrogen, the incidence of squamous metaplasia increased with age. These results indicated that squamous metaplasia is caused by some factors other than hormone induced stimulation or chronic infection, as suggested by Ito et al.?

Lymphocytic infiltration was seen in 9 aged dogs. Of these dogs, 3 had macroscopic abnormalities and were histologically diagnosed as having follicular cystitis ${ }^{5}$. None of the aged dogs had glandular cystitis or cystic cystitis which are detected with high incidence in humans. These findings concerning cystitis seem to represent a difference between dogs and humans. There was no evident relationship between lymphocytic infiltration and any other mucosal change. The low incidence of lymphocytic infiltration in aged dogs (18.0\%), when compared to humans, seems to be explained by the fact that these aged dogs had been raised in a constant environment after birth. In other words, we may say that unlike humans, who are exposed to numerous environmental factors which cause or promote bladder cancer ${ }^{10-13}$, our dogs had not been exposed to risk factors for carcinogenesis, probably resulting in a favorable influence on their urine features ${ }^{14,15}$ and immunity.

Simple hyperplasia was a common change observed in aged dogs. The incidence of this change did not differ between male and female dogs. This change had no evident relationship with lymphocytic infiltration. Its correlation with chronic inflammatory changes was also unlikely. In previous studies of experimentally induced bladder tumor in rats ${ }^{16,17}$, simple hyperplasia was 
identified as a reversible change of the normal mucosa. In the present study, this change was absent in young dogs but frequently seen in aged dogs. Therefore, aging-caused changes in urine properties, hormonal activity, and immunity seem to be involved in this change, resembling the etiology of lymphocytic infiltration.

Atypia of the mucosal epithelium was observed in 14 aged dogs. In all of these 14 dogs, only the transitional epithelium was atypical. The epithelium of the Brunn's nests did not show atypia. Atypia was more frequently seen in the part of simple hyperplasia. These findings suggest that the changes may later be followed by tumor formation. However, its relationship with carcinogenesis is not clear.

In young dogs, Brunn's nests were the only mucosal change observed. This suggests that mucosal changes such as squamous metaplasia, lymphocytic infiltration, simple hyperplasia, and atypia are related to aging.

The usefulness of experimental animals, in particular beagle dogs, in studying the development and progression of human bladder carcinoma has already been reported ${ }^{18}$. These findings from the histopathological examination of the bladder epithelium of aged dogs will serve as basic data in future studies of bladder carcinogenesis and natural history of bladder tumor in dogs.

Acknowledgements: This work was supported by Grants-in-Aid for Cancer Research from the Ministry of Health and Welfare and from the Ministry of Education, Science and Culture.

\section{References}

1. Okajima, E, Hiramatsu, T, Hirao, K, Ijuin, M, Hirao, Y, Babaya, K, Ikuma, S, Ohara, S, Shiomi, T, Hijioka, T, and Ohishi, $\mathrm{H}$ : Urinary bladder tumors induced by $\mathrm{N}$-Butyl-N-(4-hydroxybutyl) nitrosamine in dogs. Cancer Res 41 : 1958-1966, 1981.

2. Samma, S, Uemura, H, Tabata, S, Iwai, A, Nakatsuji, F, Matsuki, H, Babaya, K, Hirao, Y, and Okajima, E : Rapid induction of carcinoma in situ in dog urinary bladder by sequential treatment with $\mathrm{N}$ methyl-N' $\mathrm{N}^{\prime}$-nitrosourea and N-butyl-N-(4-hydroxybutyl)nitrosamine. Gann 75 : 385-387, 1984.

3. Shirai, T, Fukushima, S, Hirose, M, Ohshima, M, and Ito, $\mathrm{N}$ : Epithelial lesions of the urinary bladder in three hundred and thirteen autopsy cases. Jpn J
Cancer Res (Gann) 78 : 1073-1080, 1987.

4. Japanese Urological Association and the Japanese Pathological Society : General Rule for Clinical and Pathological Studies on Bladder Cancer. Kanehara Press Inc., Tokyo, 1980.

5. Koss, LG : Tumors of the urinary bladder. Atlas of Tumor Pathology, Fascicle 11. Washington : Armed Forces Institute of Pathology, 1975.

6. Wiener, DP, Koss, LG, Sablay, B, and Freed, SZ : The prevalence and significance of Brunn's nests, cystitis cystica and squamous metaplasia in normal bladders. J Urol 122: 317-321, 1979.

7. Ito, N, Hirose, M, Shirai, T, Tsuda, H, Nakanishi, K, and Fukushima, $\mathrm{S}$ : Lesions of the urinary bladder epithelium in 125 autopsy cases. Acta Pathol Jpn 31 : 545-557, 1981.

8. Packham, DA : The epithelial lining of the female trigone and urethra. Br J Urol 43: 201-205, 1971.

9. Widran, J, Sanchez, R, and Gruhn, J : Squamous metaplasia of the bladder : A study of 450 patients. J Urol 112: 479-482, 1974.

10. Fukushima, S, Thamavit, W, Kurata, Y, and Ito, N : Sodium citrate: A promoter of bladder carcinogenesis. Jpn J Cancer Res (Gann) 77: 1-4, 1986.

11. Fukushima, S, Kurata, Y, Shibata, M, Ikawa, E, and Ito, N : Promoting effect of sodium 0 -phenylphenate and o-phenylphenol on two-stage urinary bladder carcinogenesis in rats. Gann 74: 625-632, 1983.

12. Cohen, SM, Arai, M, Jacobs, JB, and Friedell, GH : Promoting effect of saccharin and DL-tryptophan in urinary bladder carcinogenesis. Cancer Res 39: 1207-1217, 1979.

13. Ito, N, Fukushima, S, Shirai, $T$, and Nakanishi, $K$ : Effects of promoters on $\mathrm{N}$-butyl-N-(4-hydroxybutyl)nitrosamine-induced urinary bladder carcinogenesis in the rat. Environ Health Perspect 50 : 61-69, 1983.

14. Ito, N, Makiura, S, Yokota, Y, Kamamoto, $Y$, Hiasa, $Y$, and Sugihara, $\mathbf{S}:$ Effect of unilateral ureter ligation on development of tumors in the urinary system of rats treated with $\mathrm{N}$-butyl-N-(4hydroxybutyl)nitrosamine. Gann 62: 359-365, 1971.

15. Oyasu, R, Iwasaki, T, Matsumoto, M, Hirao, $Y$, and Tabuchi, $Y$ : Induction of tumors in heterotopic bladder by topical application of $\mathbf{N}$-methyl- $\mathbf{N}$ nitrosourea and $\mathrm{N}$-butyl-N-(3-carboxypropyl) nitrosamine. Cancer Res 38 : 3019-3025, 1978.

16. Ito, $\mathbf{N}$ : Bladder cancer : Development, progression and its modification. Tr Soc Pathol Jpn 75 : 3-37, 1986.

17. Fukushima, S, Murasaki, G, Hirose, M, Nakanishi, $\mathrm{K}$, Hasegawa, $\mathbf{R}$, and Ito, $\mathbf{N}$ : Histopathological analysis of preneoplastic changes during $\mathrm{N}$-butyl$\mathbf{N}$-(4-hydroxybutyl)nitrosamine-induced urinary bladder carcinogenesis in rats. Acta Pathol Jpn 32 : 243-250, 1982. 